\title{
Voltage measurements at the vacuum post-hole convolute of the $Z$ pulsed-power accelerator
}

\author{
E. M. Waisman, ${ }^{1}$ R. D. McBride, ${ }^{1}$ M. E. Cuneo, ${ }^{1}$ D. F. Wenger, ${ }^{1}$ W. E. Fowler, ${ }^{1}$ W. A. Johnson, ${ }^{1}$ \\ L. I. Basilio, ${ }^{1}$ R. S. Coats, ${ }^{1}$ C. A. Jennings, ${ }^{1}$ D. B. Sinars,${ }^{1}$ R. A. Vesey, ${ }^{1}$ B. Jones, ${ }^{1}$ \\ D. J. Ampleford, ${ }^{1}$ R. W. Lemke, ${ }^{1}$ M. R. Martin, ${ }^{1}$ P. C. Schrafel, ${ }^{1,2}$ S. A. Lewis, ${ }^{1}$ \\ J. K. Moore, ${ }^{1}$ M. E. Savage, ${ }^{1}$ and W. A. Stygar \\ ${ }^{1}$ Sandia National Laboratories, Albuquerque, New Mexico 87185, USA \\ ${ }^{2}$ Laboratory of Plasma Studies, Cornell University, Ithaca, New York 14853, USA
}

(Received 28 April 2014; published 8 December 2014)

\begin{abstract}
Presented are voltage measurements taken near the load region on the $Z$ pulsed-power accelerator using an inductive voltage monitor (IVM). Specifically, the IVM was connected to, and thus monitored the voltage at, the bottom level of the accelerator's vacuum double post-hole convolute. Additional voltage and current measurements were taken at the accelerator's vacuum-insulator stack (at a radius of $1.6 \mathrm{~m}$ ) by using standard $D$-dot and $B$-dot probes, respectively. During postprocessing, the measurements taken at the stack were translated to the location of the IVM measurements by using a lossless propagation model of the $Z$ accelerator's magnetically insulated transmission lines (MITLs) and a lumped inductor model of the vacuum post-hole convolute. Across a wide variety of experiments conducted on the $Z$ accelerator, the voltage histories obtained from the IVM and the lossless propagation technique agree well in overall shape and magnitude. However, large-amplitude, high-frequency oscillations are more pronounced in the IVM records. It is unclear whether these larger oscillations represent true voltage oscillations at the convolute or if they are due to noise pickup and/or transit-time effects and other resonant modes in the IVM. Results using a transit-time-correction technique and Fourier analysis support the latter. Regardless of which interpretation is correct, both true voltage oscillations and the excitement of resonant modes could be the result of transient electrical breakdowns in the post-hole convolute, though more information is required to determine definitively if such breakdowns occurred. Despite the larger oscillations in the IVM records, the general agreement found between the lossless propagation results and the results of the IVM shows that large voltages are transmitted efficiently through the MITLs on $Z$. These results are complementary to previous studies [R. D. McBride et al., Phys. Rev. ST Accel. Beams 13, 120401 (2010)] that showed efficient transmission of large currents through the MITLs on $Z$. Taken together, the two studies demonstrate the overall efficient delivery of very large electrical powers through the MITLs on $Z$.
\end{abstract}

DOI: 10.1103/PhysRevSTAB.17.120401

PACS numbers: 52.58.Lq, 84.70.+p

\section{INTRODUCTION}

The refurbished $Z$ pulsed-power accelerator [1-4] delivers approximately 3-MV, 25-MA, 100-600-ns electrical pulses to various loads for research efforts in inertial confinement fusion (ICF) [5-8], pulsed-power physics [9-12], z-pinch physics [13,14], $K$-shell x-ray sources [15], radiation physics [16,17], fundamental science and laboratory astrophysics $[18,19]$, dynamic material properties [20-23], and other high-energy-density physics applications [24].

The architecture of the refurbished $Z$ accelerator is discussed in detail in Refs. [3,4]. It is based on 36 Marxgenerator-driven pulse-forming-line modules connected

Published by the American Physical Society under the terms of the Creative Commons Attribution 3.0 License. Further distribution of this work must maintain attribution to the author(s) and the published article's title, journal citation, and DOI. electrically in parallel (Fig. 1). Each of the 36 Marx generators contains $602.6-\mu \mathrm{F}$ capacitors. When the capacitors are charged to $90 \mathrm{kV}, Z$ stores approximately $23 \mathrm{MJ}$ of electrical energy.

Since $Z$ is a Marx-waterline pulsed-power machine, several stages of pulse compression are used for achieving overall pulse compression and power amplification, as well as pulse-shaping capabilities. Referring to Fig. 1, we see that each Marx generator is discharged into a coaxial intermediate storage capacitor (ISC). Each ISC is subsequently discharged through a laser-triggered gas switch (LTGS) into a coaxial pulse-forming line (PFL). Each PFL is discharged through a self-breaking main water switch into a first output transmission line (OTL1). Each OTL1 is discharged through a peaking water switch into a second output transmission line (OTL2). The OTL2s combine pairs of OTL1 outputs into single OTL2 outputs that feed the water convolute. The water convolute then makes the connection from the 18 OTL2 outputs to four electrically 


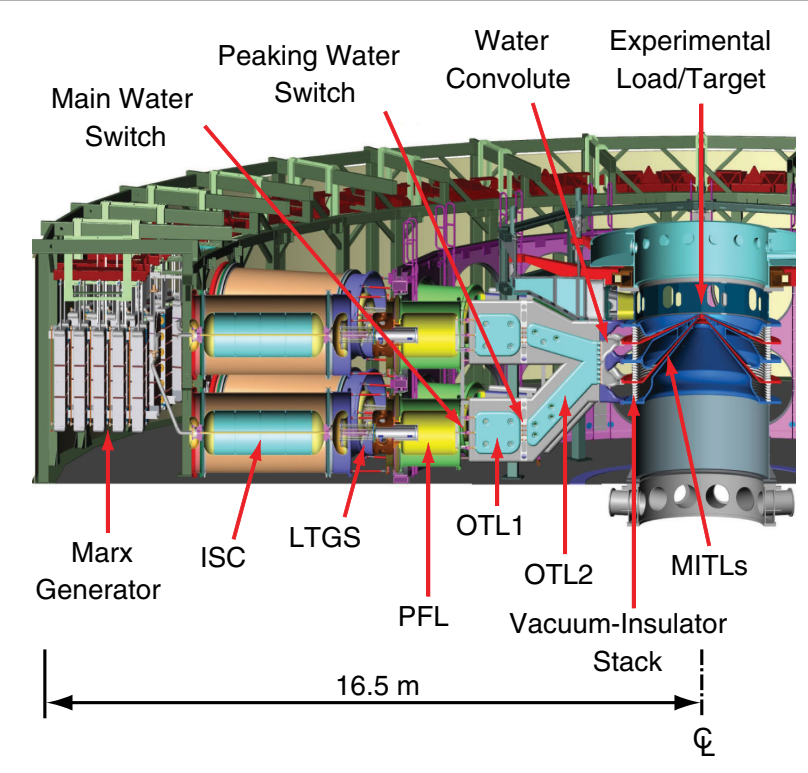

FIG. 1. Cross-sectional drawing of one radial half of the refurbished $Z$ pulsed-power accelerator. The various components and stages are described in the text.

parallel conducting rings at the vacuum-insulator stack. Each ring connects to one of four electrically parallel vacuum magnetically insulated transmission lines (MITLs) [10]. The four MITLs are then connected to a single innerMITL feed by a double post-hole convolute [25]. Finally, the inner-MITL feed connects to the experimental load under test (e.g., a z-pinch target).

At the vacuum-insulator stack, which is at a radial position of about $1.6 \mathrm{~m}$ from the $Z$ axis of symmetry, voltage $(\dot{\mathrm{D}})$ and current $(\dot{\mathrm{B}})$ measurements are made on all four levels and at multiple azimuthal locations (Fig. 2) $[26,27]$. Current $(\dot{\mathrm{B}})$ measurements are also made near the experimental load, at a radial position of about $6 \mathrm{~cm}$ from the $Z$ axis of symmetry, and again at multiple azimuthal angles (Fig. 2) [26,28]. For a typical experiment on $Z$, approximately $16 \dot{D}$ and $16 \dot{B}$ probes are used on each of the four levels of the vacuum-insulator stack, and four to eight $\dot{B}$ probes are used at the load. Because of the number of probes used, the relative $2 \sigma$ random uncertainty is about $1 \%$ for the averaged voltage and averaged current measured at the stack and about $2 \%-5 \%$ for the averaged current measured at the load [26].

The voltages and currents measured at each of the vacuum-insulator stack's four levels can be translated to the post-hole convolute location by using a lossless transmission-line-equivalent (TLE) model of the four-level MITL system [10,12,29-32]. In Ref. [32], lossless TLEtranslated current waveforms were compared to and found to agree well with measured load current waveforms, thus demonstrating efficient current transmission through the MITLs on Z. To perform similar comparisons using voltage waveforms, however, requires that voltage

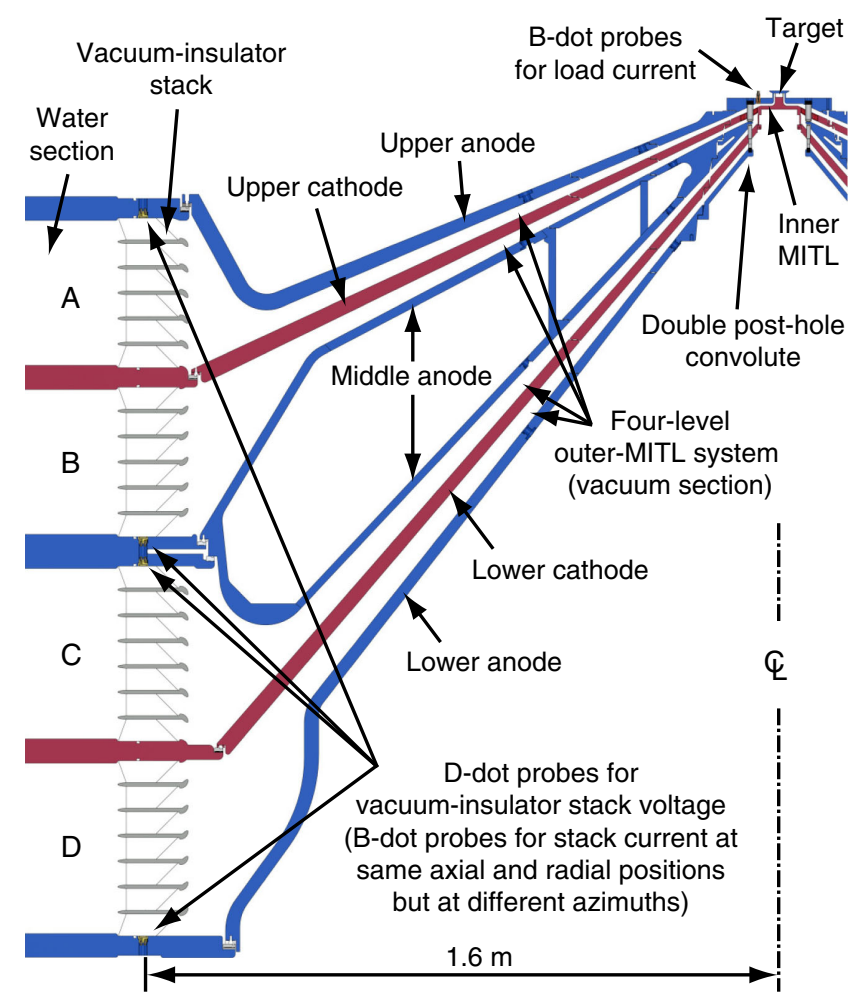

FIG. 2. Cross-sectional drawing of one radial half of the refurbished $Z$ vacuum section.

measurements be taken downstream of the MITLs on $Z$. To this end, we have developed an inductive voltage monitor (IVM) for $Z$. Other approaches are certainly possible, e.g., resistive dividers [33,34] and/or vacuum transmission line voltmeters [35]; however, we chose the IVM approach for its relative simplicity, lower cost, and lower potential for debris damage to the accelerator. The results of fielding this IVM on a wide variety of $Z$ experiments is the subject of the remainder of this paper, which is organized as follows. In Sec. II, we describe the implementation of the IVM. In Sec. III, we provide an analytic approximation for the inductance of the IVM; this approximation is validated by the results of a lowfrequency 3D simulation which is also presented. In Sec. IV, we employ a transit-time-correction technique [30] and perform Fourier analysis of the data to obtain the IVM frequency response beyond the zero-frequency inductive approximation. We then report the results of applying this analysis to the data from six different experiments on Z. In Sec. V, we summarize our results and present our conclusions.

\section{DESCRIPTION OF THE INDUCTIVE VOLTAGE MONITOR}

A half-section illustration of the IVM is provided in Fig. 3. The IVM is an L-shaped assembly of 


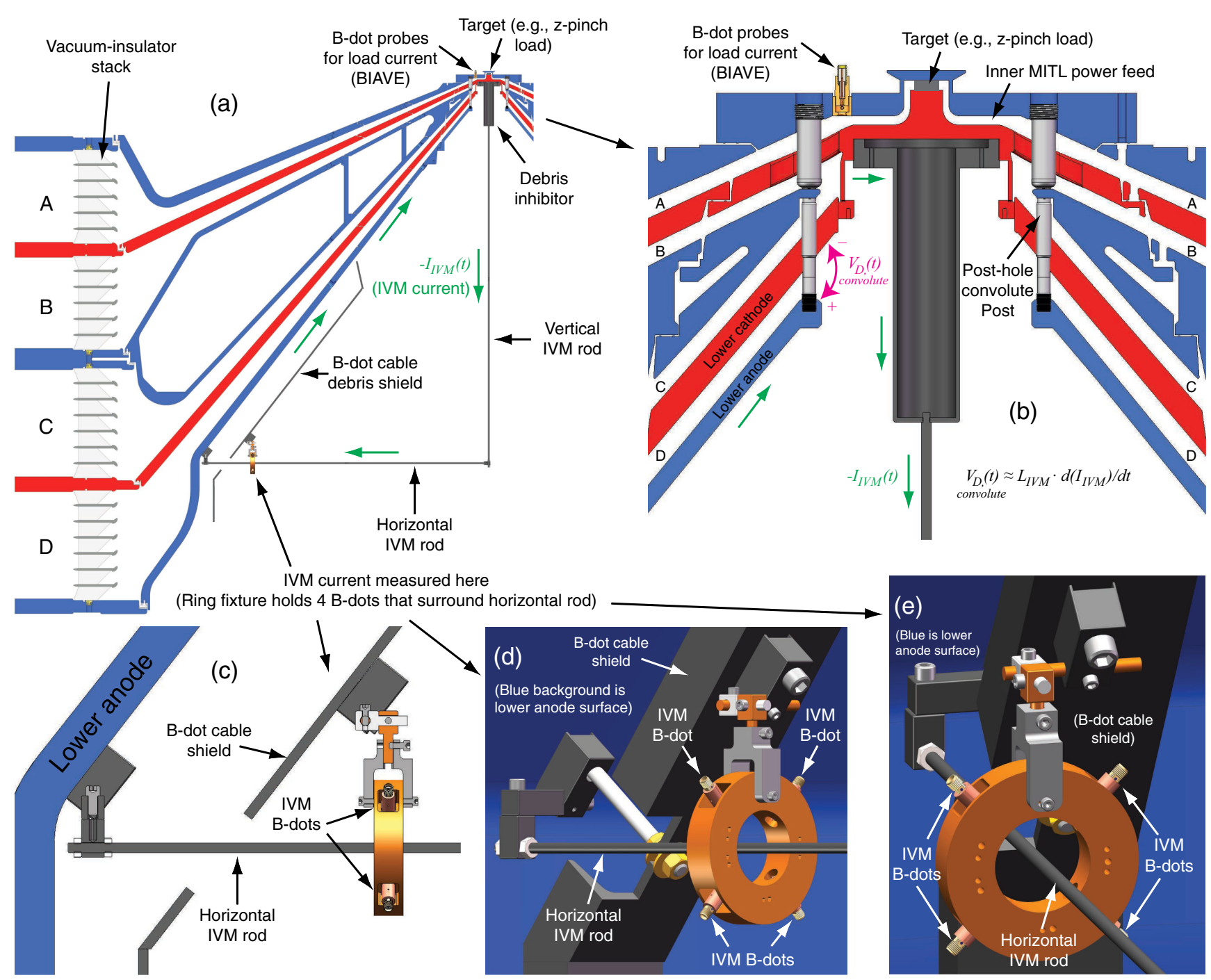

FIG. 3. (a) Cross-sectional illustration of the IVM installed in the lower volume of the $Z$ vacuum section, below the four MITLs, where only the left radial half of the $Z$ vacuum section is shown. (b) Zoomed-in cross-sectional illustration of the $Z$ accelerator's double post-hole convolute region, highlighting the IVM's upper connection point. (c) Zoomed-in crosssectional illustration of the IVM's lower connection point, highlighting the IVM's $B$-dot probes, which are used to obtain the current carried by the IVM. (d), (e) Slightly rotated versions of that shown in (c), highlighting how the electrical and structural connections are made.

two thin conducting rods, one vertical and one horizontal, fielded within the vacuum section of the $Z$ pulsedpower accelerator. The vertical rod $(\sim 1 \mathrm{~m}$ in length) runs along the accelerator's $z$ axis of cylindrical symmetry. The top of the vertical rod is connected to the bottom of the accelerator's double post-hole convolute, which is part of the accelerator's cathode structure just below the experimental load under test (e.g., a z-pinch load). The horizontal $\operatorname{rod}(\sim 1 \mathrm{~m}$ in length) then connects the bottom of the vertical rod to the accelerator's lower anode. Four $\dot{B}$ probes, configured as two differential pairs to reduce common-mode noise, measure the time derivative of the current flowing in the IVM. In the inductive approximation, the IVM thus provides the voltage at the bottom level (i.e., the $D$ level) of the double posthole convolute. ${ }^{1}$

Three versions of the IVM with different rod lengths were tested during various $z$-pinch experiments on $Z$. The three versions tested are described in Table I. All three IVM versions had inductance values on the order of a few $\mu \mathrm{H}$ (see Sec. III), while the inductance values for the $z$-pinch

\footnotetext{
${ }^{1}$ Note that the IVM on $Z$ is similar in implementation to various inductive voltage probes fielded previously on other pulsedpower machines; see, for example, the inductive load voltage monitors fielded on the Angara-5-1, COBRA, and MAGPIE machines [36-39]. In fact, the IVM on $Z$ was inspired by the Angara-5-1 probe.
} 
TABLE I. IVM dimensions and calculated inductance for the three versions implemented.

\begin{tabular}{lcrcc}
\hline \hline IVM version & $l_{h}[\mathrm{~cm}]$ & $l_{v}[\mathrm{~cm}]$ & $r_{0}[\mathrm{~cm}]$ & $L[\mu \mathrm{H}]$ \\
\hline I $(Z)$ & $116 \pm 0.6$ & $98 \pm 4$ & 0.3175 & $2.04 \pm 0.06$ \\
II (refurbished $Z$ ) & $120 \pm 0.6$ & $155 \pm 4$ & 0.3175 & $2.76 \pm 0.05$ \\
III (refurbished $Z$ ) & $74 \pm 0.6$ & $97 \pm 4$ & 0.3175 & $1.55 \pm 0.05$ \\
\hline \hline
\end{tabular}

loads were on the order of $10 \mathrm{nH}$. Thus, on a given experiment, roughly $1 \%$ of the total load current was diverted through the IVM.

\section{IVM INDUCTANCE}

The $B$-dot probes shown in Fig. 3 in Sec. II measure the time derivative of the current flowing in the IVM, which, in the lumped-inductor limit, is considered to be constant along the rods. The convolute post-hole gap voltage of level $D$ (see Fig. 4) is then given by

$$
V_{D, \text { conv }}=L_{\text {probe }} I_{\text {probe }},
$$

where $V_{D \text {,conv }}$ is the voltage between the $D$-level anode post and the cathode plate, with the voltage in $\mathrm{V}$, the current in $\mathrm{A}$, and the inductance in $\mathrm{H}$.

To obtain the probe inductance, we have to evaluate $\int_{S} B_{\perp} d r d z$. To that effect, we consider Fig. 5 showing schematically the IVM rods, the vertical connected to the cathode and the horizontal to the anode (ground). The rods are of lengths $l_{v}$ and $l_{h}$ (see Fig. 5 for the definition of $l_{h}$ and $l_{v}$ ), respectively, and have radius $r_{0}$.

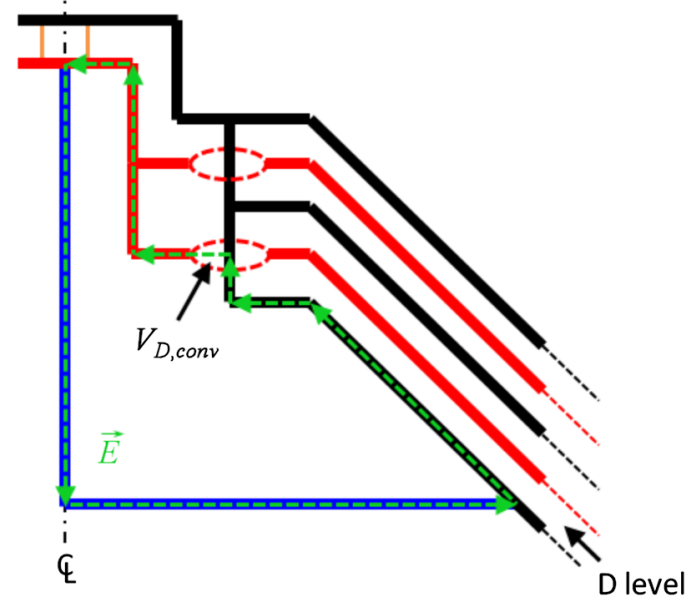

FIG. 4. Schematic, not to scale, showing the load as thin orange lines, the anodes as thick black lines, and the cathodes as thick red lines. The IVM is represented by blue lines. All parts of the drawing depict axisymmetric structures, with the exception of the horizontal IVM rod, and the convolute posts and holes. The loop shown is to calculate the line integral of the electric field resulting in the voltage $V_{D \text {,conv }}$ : the potential difference between the posthole gap at the $D$ level of the vacuum convolute.

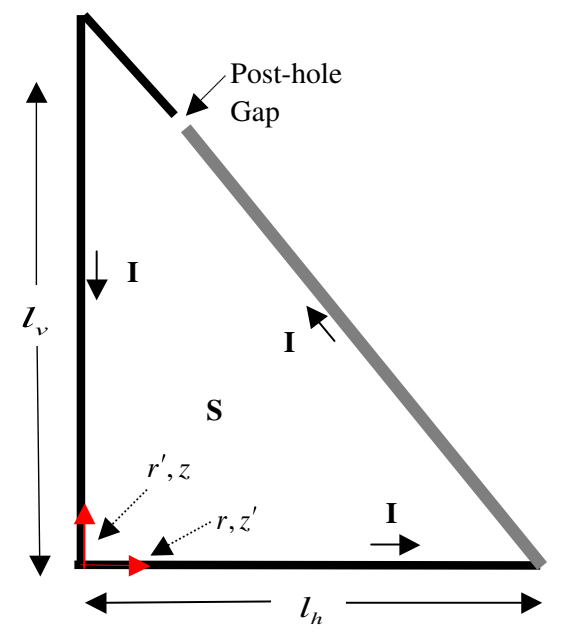

FIG. 5. Plane of the IVM and, in red, the coordinate systems used to calculate its inductance. The voltage is applied at the gap shown in the figure. The gray thick line represents the lower anode (ground) of the accelerator.

Both rods carry the same current $I_{\text {probe }}$, which is constant along the rods in the lumped inductance approximation. To obtain a useful analytic expression for the probe inductance, we approximate the field of each rod as the field from an infinitely long wire $B[G]=I[A] / 5 r[\mathrm{~cm}]$ and assume the field linking the IVM circuit can be represented by $B_{1}+B_{2}$, where 1 and 2 refer to the two rods. Thus we have

$$
B_{\perp} \simeq B_{1}+B_{2}=0.2 I_{\text {probe }}\left(1 / r+1 / r^{\prime}\right),
$$

where $B$ is in Gauss, $I$ in A, the radii are in centimeters, and $r, r^{\prime}$ are the radial distances from the vertical and horizontal rod axes, respectively. This approximation overestimates the fields from the finite-length rods but compensates for neglecting the field from the current in the conical inner surface of the MITL connecting the rod ends. Below, we will use the results of a 3D electromagnetic calculation to show that this approximation results in an accurate value of the IVM inductance. In this approximation, then, the probe inductance is

$$
L_{\text {probe }}[H]=2 \times 10^{-9}\left(\int_{0}^{z_{0}} d z \int_{r_{0}}^{r(z)} d r / r+\int_{r_{0}}^{z_{0}^{\prime}} d z \int_{r_{0}^{\prime}}^{r^{\prime}(z)} d r / r\right),
$$

where $r(z)=l_{h}-z l_{h} / l_{v}$ and $z_{0}=l_{v}-r_{0} l_{v} / l_{h}$ for the first integral and $r^{\prime}(z)=l_{v}-z^{\prime} l_{v} / l_{h}$, and $z_{0}^{\prime}=l_{h}-r_{0} l_{h} / l_{v}$ for the second one. The integrals of Eq. (3) are easily obtained in analytic form.

In Table I, we show the inductance values obtained from Eq. (3) for the three versions of the IVM given their corresponding values of $l_{v}, l_{h}, r_{0}$.

To validate this inductance approximation, we performed a 3D electromagnetic calculation for the first version of the IVM. This was done by using the EIGER [40] code, which is a frequency domain boundary element electromagnetic 


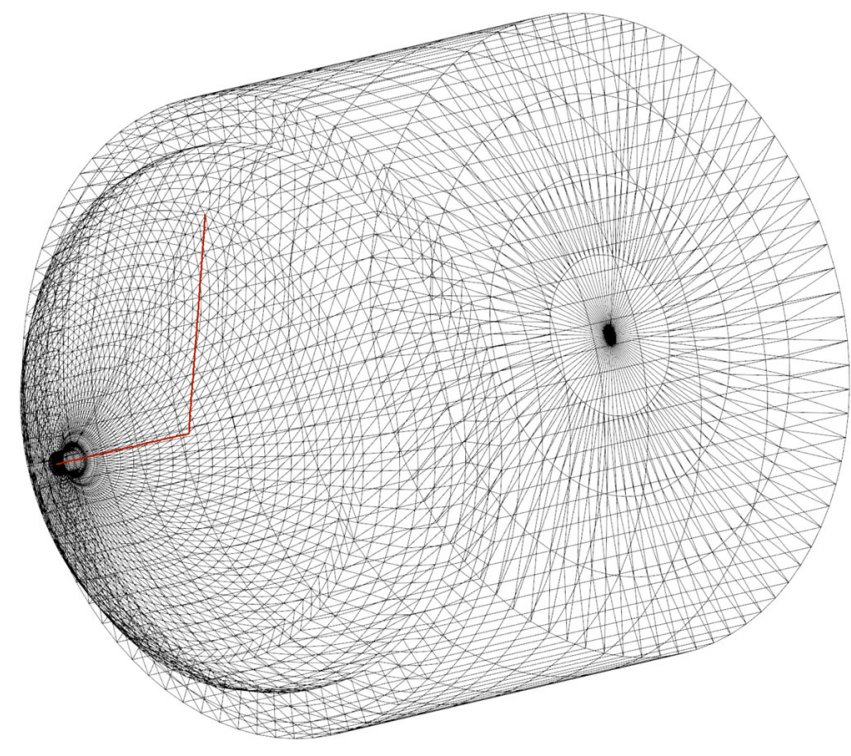

FIG. 6. Boundary element mesh used in the EIGER calculation of the IVM inductance. A high-density mesh is used along the angular dimension of the cavity surface in order to capture the modal variation excited at the junction of the horizontal wire section and the cavity wall.

code with the capability to model a wire attached to an enclosed cavity surface (see the mesh used to model this system in Fig. 6). Using a low frequency $(\nu=7500 \mathrm{~Hz})$, we obtained the inductance by driving the code with a $1-\mathrm{V}$ voltage source and extracting the current on the wire. Since $l \nu / c \ll 1$, where $l$ is the IVM characteristic length, the quantity $\nu I$ is constant along the wire, with the inductance being given by $L=|V / I \omega|, \nu=\omega / 2 \pi$. EIGER takes advantage of using the thin wire Green's function, thus providing the required accuracy for the electromagnetic field's spatial dependence near the IVM thin rods. The mesh that was used to model the cavity surface was refined to accurately resolve the horizontal wire junction at the cavity wall and to capture the angular mode distribution along the cavity wall excited by this wire section. By using 80 mesh elements along the angular direction of the cavity wall, the simulated current converged, and we obtained $L=2.03 \mu \mathrm{H}$. This agrees to better than $1 \%$ with the approximate analytic solution, which is provided in Table I.

Also provided in Table I are the estimated inductance uncertainties, which are about $3 \%$ and are due primarily to the uncertainties in $l_{v}$ and $l_{h}$. The rod lengths are known only approximately, because they connect to structures with geometries that are more complex than that of our simple "L" shape approximation (see Fig. 3). In Table I, we have provided our best estimates for the effective lengths of the rods, with both upper and lower bounds. Note that, because of these inductance uncertainties, the uncertainties in the voltages measured by the IVM are also about 3\% [cf. Eq. (1)].

In Figs. 7(a)-7(c), we present results from three experiments on $Z$ : shots 1177,2105 , and 2172, which correspond to the three IVM versions shown in Table I. Here we have
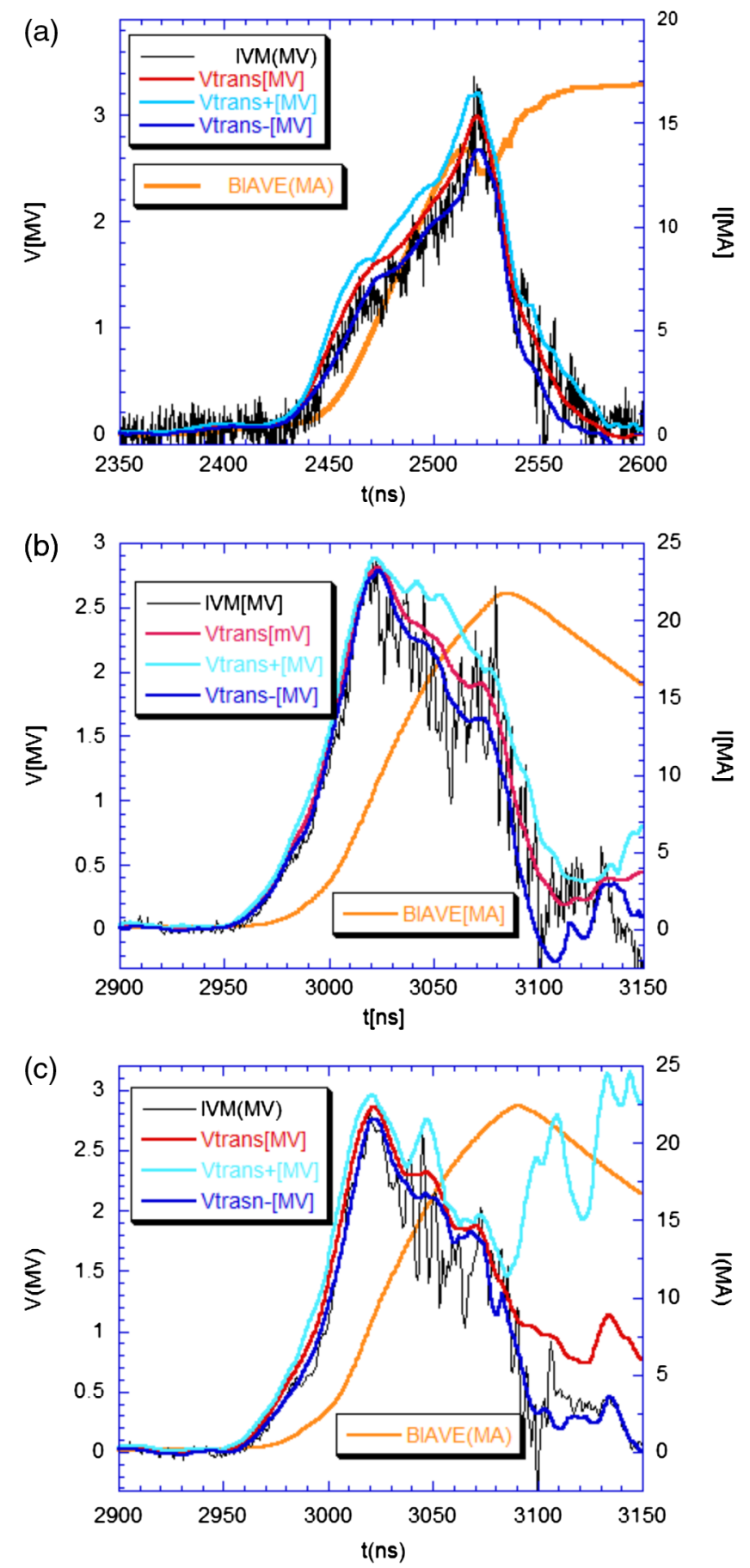

FIG. 7. Voltage comparisons at the $D$-level post-hole gap of the vacuum convolute for (a) shot 1177 ( $Z$ prerefurbishment, IVM implementation I), (b) shot 2105 (IVM implementation II), and (c) shot 2172 (IVM implementation III). The red curves are the TLEtranslated results (averaged over the four MITL-convolute levels), and the black curves are the IVM results obtained by using Eq. (1). The light blue and dark blue curves are upper and lower bounds, respectively, for the TLE translations, obtained as explained in the text. The orange curve is the inner MITL load current BIAVE, measured $6 \mathrm{~cm}$ from the machine axis of symmetry. Shot 2172 exhibits large errors after about $3030 \mathrm{~ns}$ and then again after $3090 \mathrm{~ns}$ in the translated voltage due to the flashing of the vacuum-insulator stack's $B$ level; interestingly, the onset of large IVM voltage oscillations coincides with the first instance of flashing at $3030 \mathrm{~ns}$. 
plotted the voltage waveforms obtained from the IVM by using Eq. (1). We have also plotted the voltage waveforms obtained by TLE-translating electrical measurements taken at the vacuum-insulator stack to the entrance of the double post-hole convolute and then applying the appropriate $L(d I / d t)$ voltage corrections to account for the $\sim 1-\mathrm{nH}$ inductances between each level in the convolute [41]. Since the electromagnetic transit time through the convolute is $\sim 0.1 \mathrm{~ns}$, the lumped inductor approximation for the convolute is well justified. The four TLE-translated waveforms, $L(d I / d t)$ corrected to the $D$ level in the convolute, were then averaged together and plotted in red in Fig. 7. For reference, we have also plotted in Fig. 7 the $Z$ accelerator's load current for each experiment, measured within the inner MITL, $6 \mathrm{~cm}$ from the cylindrical axis of symmetry, and referred to as BIAVE.

Figure 7 shows that the IVM and the translated voltage waveforms agree well in overall shape, timing, and amplitude. However, very large oscillations are present in the IVM waveforms for shots 2105 and 2172. It is because of these large oscillations, first observed with the earlier IVM version II, that the rod lengths were shortened in going from IVM version II to III. This was done to test whether a smaller probe structure would affect either the amplitude or the frequency of the large oscillations observed when using IVM version II. As can be seen by comparing shots 2105 and 2172, no clearly identifiable effects are readily apparent.

We also show in Fig. 7 the upper and lower bounds for the TLE-translated voltages. These bounds are obtained by considering the following. The four MITLs are connected electrically in parallel at the post-hole convolute. Thus, the results of the four parallel TLE translations (one for each MITL level) would agree in the ideal limit, since they are translated to the same location, i.e., the $D$ level of the double post-hole vacuum convolute, which is also the location of the independent measurement obtained by the IVM. However, due to measurement error and TLEtranslation error, we get four TLE-translated results that disagree somewhat. The averages of the four TLE translations (corrected to the convolute $D$ level) are plotted as the nominal translation results in Fig. 7, while the upper and lower bounds show the maximum and minimum values obtained from the four TLE translations.

For shot 2172, the $B$ level flashed (i.e., partially shorted) at the vacuum insulator stack starting at about $3030 \mathrm{~ns}$ and then again at about $3090 \mathrm{~ns}$; this is responsible for the large deviations of the upper and lower bounds for the translated voltages shown in Fig. 7(c) after these times. It is interesting that the onset of the large oscillations in the IVM curve approximately coincides with the first instance of flashing near $3030 \mathrm{~ns}$. Although this is suggestive of the IVM measurement being more representative of true voltage transients occurring at the convolute, we do not have enough evidence to state this unequivocally. It is also possible that fast voltage events, such as stack flashing or convolute arcing, could excite resonant modes in the IVM.

\section{IVM TRANSIT-TIME CORRECTION AND FREQUENCY RESPONSE}

The presence of large oscillations in the IVM waveforms has motivated the application of a transit-time-correction technique developed in Ref. [30]. This technique consists of approximating the IVM as a single transmission line, characterized by its impedance and its one-way transit time. Since we measure the current in the horizontal IVM rod, and since the voltage at the horizontal rod is zero, we can write

$$
V_{T T}(t)=Z_{\text {probe }}\left[I_{\text {probe }}(t+\tau)-I_{\text {probe }}(t-\tau)\right] / 2,
$$

where $Z_{\text {probe }}=L_{\text {probe }} / \tau$.

In Eq. (4), $V_{T T}(t)$ stands for the transit-time-corrected IVM voltage measurement. The one-way transit time $\tau$ is only approximately known, but it is between 4 and $7 \mathrm{~ns}$, which we determined by using the probe geometry to put upper and lower bounds on the path length and then dividing the possible path lengths by the speed of light in vacuum. We found the transit-time-correction results to be insensitive to transit-time choices in this range, so we selected $6 \mathrm{~ns}$ for our analysis.

We also performed Fourier analysis to study the IVM frequency response, which we now describe. Both techniques are employed in an attempt to determine if the IVM oscillations are representative of true voltage oscillations at the convolute, or if they are simply the result of excited resonant modes in the IVM structure, such as transit-time effects. Here we analyze the data corresponding to IVM implementation II of Table I, because it was used on the largest number of shots.

The Fourier transforms of $V(t)=V_{D, \text { conv }}(t)$, the $D$-level post-hole gap voltage, and $\dot{I}(t)=\dot{I}_{\text {probe }}(t)$, the time derivative of the current measured at the location of the IVM $B$ dots, are given by

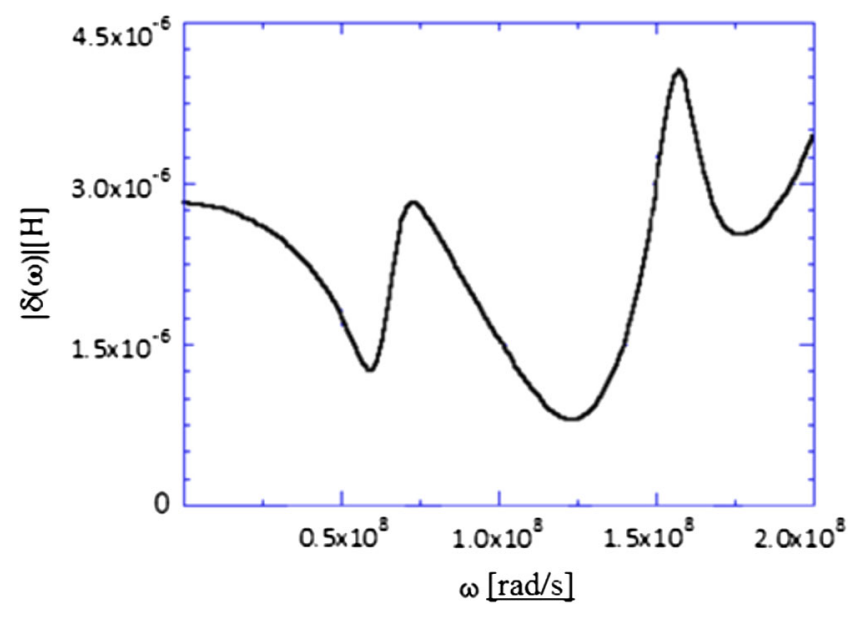

FIG. 8. Modulus of the ratio of the Fourier transforms of the TLE-translated voltage waveform and the time derivative of the IVM current waveform for shot 2105 for low frequencies. In particular, note that $\operatorname{Re} \delta(0)=2.82 \mu \mathrm{H}$, is in good agreement with the calculated value of $L=2.76 \mu \mathrm{H}$ in Table I. 


$$
V_{\omega}=\int_{0}^{T} d t V(t) e^{i \omega t}, \quad \dot{I}_{\omega}=\int_{0}^{T} d t \dot{I}(t) e^{i \omega t} .
$$

For simplicity, the $D$-level convolute voltage used in Eq. (5) is the TLE translation of the $D$ level only (thus removing
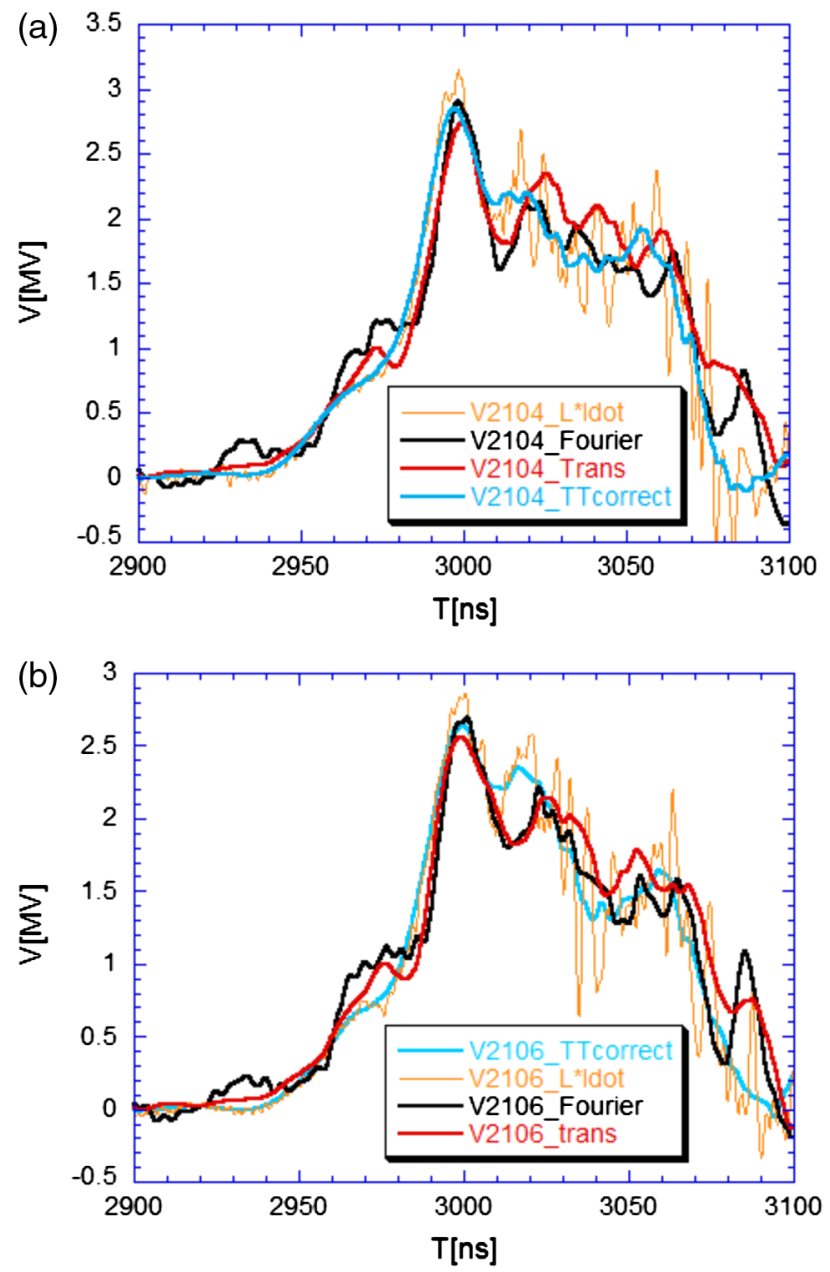
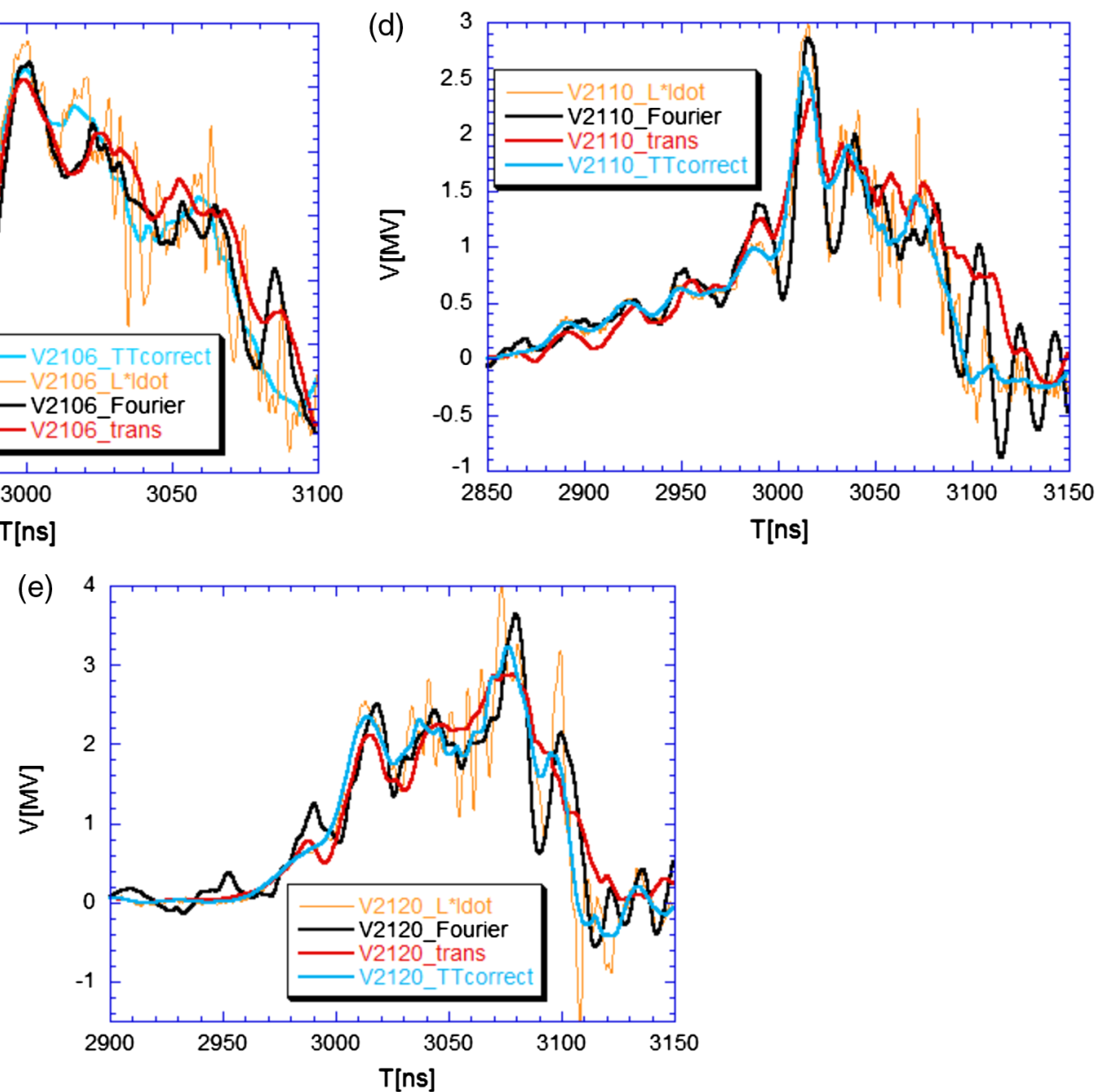

the need for inductively correcting levels $A-C$ through the double post-hole convolute to the $D$ level). We take the zero time when the voltage and current time derivative signals start to depart from zero; for $T$ in Eq. (5), we use $200 \mathrm{~ns}$ for shots 2104,2105 , and 2106 , and 300 ns for 2108,2110 , and

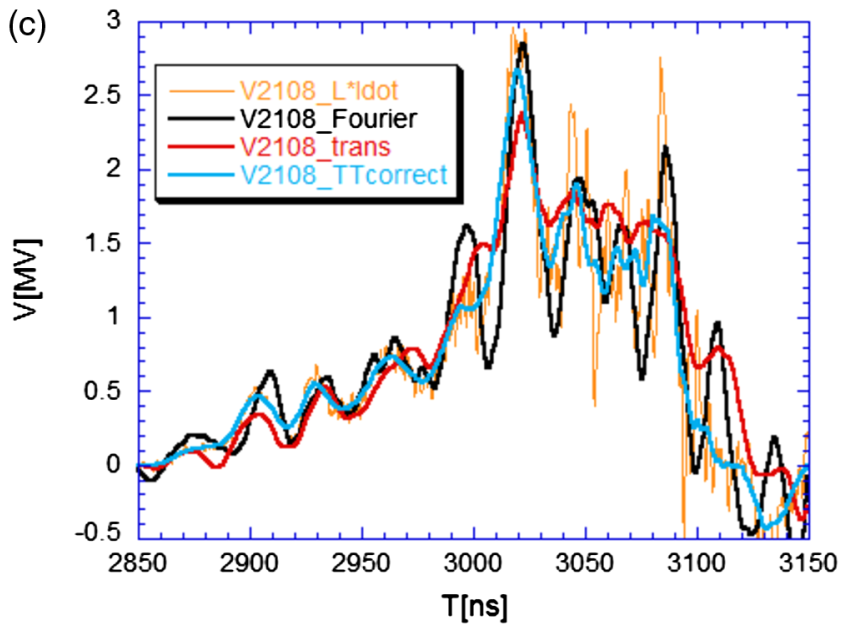

FIG. 9. (a)-(e) Comparison of voltages at the $D$-level post-hole gap of the vacuum convolute for shots 2104, 2106, 2108, 2110, and 2120 , respectively. The red curve is the TLE-translated voltage. The orange curve is obtained by using Eq. (1) with the IVM $B$-dot signals. The black curve is obtained as described in Sec. IV by using the function $\delta(\omega)$ defined in that section, for shot 2105 . The blue curve is the transit-time-corrected voltage of Eq. (4) assuming $\tau=6 \mathrm{~ns}$. 
2120. The interval $[0, T]$ corresponds to the period in which the relevant evolution of the load voltage takes place for the indicated shots. We remark that, for any given frequency, the current on the IVM rods is a function not only of time, but also of position, and in this context $\dot{I}(t)$ is the timederivative of the current as measured at the location of the $B$-dot probes.

In the absence of space charge and plasma effects in the IVM structure, the ratio $\delta(\omega)=V_{\omega} / \dot{I}_{\omega}$ of these two quantities is an invariant characteristic of the measuring device. Thus, a voltage waveform obtained from the IVM by using the function $\delta(\omega)$ should provide a more accurate representation of the true voltage at the convolute than that of the simple inductive approximation of Eq. (1).

We used shot 2105 to construct $\delta(\omega)$. We selected this shot because, for the IVM implementation II, it is the one in the series showing the smallest $\dot{I}(t)$ oscillations [see Fig. 7(b)]. Because the TLE-translated voltages do not show such large oscillations (see Fig. 7), we find it unlikely that the large oscillations in $\dot{I}(t)$ are representative of true $V_{D \text {,conv }}$ oscillations, although we cannot prove this from the information available. Furthermore, the $\dot{I}(t)$ oscillations change significantly from shot to shot, even for shots where the load and the $Z$ accelerator operation are similar. Therefore, we conjecture that the large $\dot{I}(t)$ fluctuations measured are some combination of $B$-dot noise pickup, electromagnetic transit-time effects (i.e., excited resonant modes), nonaxisymmetric wave propagation in the IVM, and/or plasma and space charge effects.

In Fig. 8, we plot for shot $2105|\delta(\omega)|$ for $\omega \leq 2 \times 10^{8} \mathrm{rad} / \mathrm{s}$. The real part of this function near zero frequency $|\delta(0)|=\operatorname{Re} \delta(0)$ is seen to be close to the calculated value for the IVM inductance, i.e., $2.82 \mathrm{nH}$ vs the $2.76 \mathrm{nH}$ in Table I.

Multiplying $\delta(\omega)$, obtained from shot 2105 , by the Fourier transform $\dot{I}_{\omega}$, obtained from the $\dot{I}(t)$ measurements for shots $2104,2106,2108,2110$, and 2120 , we obtain $V_{\omega}$ for those shots. We then take the inverse Fourier transform of $V_{\omega}$ and compare it with the translated voltages. To obtain the forward and inverse Fourier transforms we use the subroutine dftint of Numerical Recipes [42] with a cutoff frequency of $\nu_{\max }=2.5 \times 10^{8} \mathrm{~Hz}$, corresponding in the time domain to an effective sampling rate $\Delta=1 /\left(2 \nu_{\max }\right)=$ $2 \mathrm{~ns}$. The actual time data is taken at $0.2 \mathrm{~ns}$ intervals. We show in Figs. 9(a)-9(e) the $D$-level convolute voltages for the shots of IVM implementation II: 2104, 2106, 2108, 2110 , and 2120 . The plotted voltages are obtained by using Eqs. (1) and (4), the Fourier analysis described in this section, and by translation of the electrical measurements taken at the $D$ level of the vacuum-insulator stack. Figures 9(a)-9(e) show that the transit-time-correction technique and the Fourier analysis give similar results, supporting the idea that the large fluctuations obtained in the purely inductive approximation of Eq. (1) are mainly due to transit-time effects. The errors in the TLE translated voltages are similar to those discussed in Sec. III and presented in Fig. 7.

We remark that different voltage and current pulse shapes were obtained for the various shots because different loads and accelerator configurations were used. Shot 1177, shown in Fig. 7(a), corresponds to the $Z$ machine before refurbishment in short-pulse mode (100 ns) driving a tungsten wire-array $z$-pinch implosion [13]. Shots 2104 and 2106, as well as shots 2105 and 2172 , used the refurbished $Z$ accelerator in short-pulse mode (100 ns) to drive the implosions of initially solid Be liners (tubes) with high initial inductances $L_{0}$ and low rates of inductive increase $d L / d t$ due to slow implosion velocities [7]. Shots 2105 and 2172 are shown in Figs. 7(b) and 7(c), respectively, while the voltages for shots 2104 and 2106 are shown in Figs. 9(a) and 9(b). Shots 2108 and 2110 also used solid Be liner loads, but these shots used the refurbished $Z$ accelerator in pulseshaping mode to shocklessly compress the liners as they imploded over slightly longer time scales (200 ns) [7]; the voltages for these shots are shown in Figs. 9(c) and 9(d), respectively. Finally, shot 2120 used the refurbished $Z$ accelerator in short-pulse mode to drive the implosion of a wire-array $z$-pinch load that had a large initial diameter (low $L_{0}$ ) and a high implosion velocity (high $d L / d t$ ) for $K$-shell x-ray sources science [15]; the voltages for this shot are shown in Fig. 9(e). In Fig. 10, we show the various load current pulse shapes obtained for all of the experiments discussed in this paper.

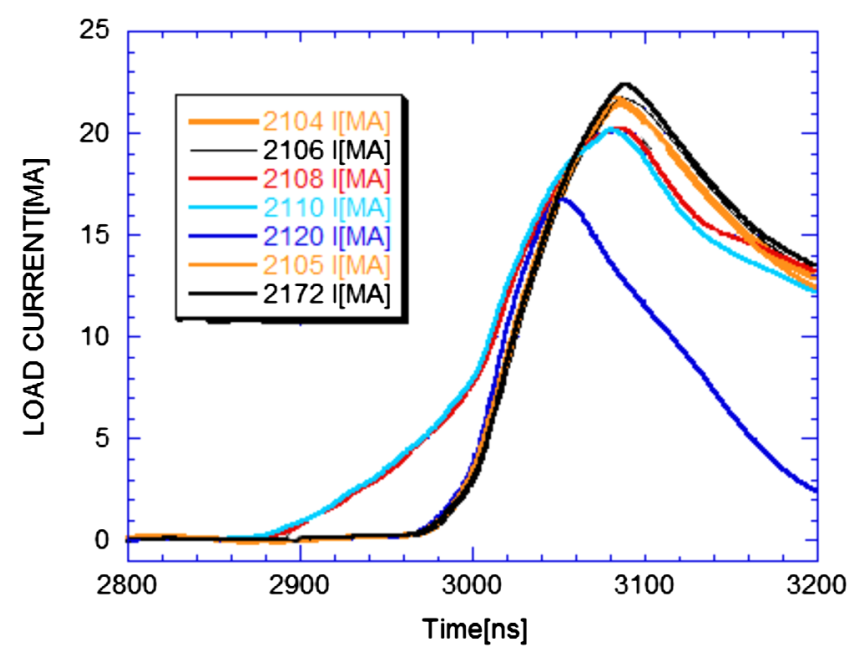

FIG. 10. Load currents from the various experiments on the refurbished $Z$ machine discussed in this paper. As described in the text, different pulse shapes were obtained because different loads and accelerator configurations were used. The load current for 1177 is shown in Fig. 7(a). 


\section{SUMMARY AND CONCLUSIONS}

We have successfully measured fast ( 100 ns) and large ( $\sim 3 \mathrm{MV}$ ) load voltages, at the bottom of the $Z$ accelerator's vacuum post-hole convolute, just below the experimental load under test. This has been done while diverting only about $1 \%$ of the $Z$ accelerator's $\sim 20$ MA of load current through the IVM probe. Moreover, we have presented results from several experimental configurations, including three different implementations of the IVM. By using the simple inductive approximation of Eq. (1), IVM voltage waveforms were compared to the voltage waveforms obtained by TLE-translating voltage and current measurements losslessly from the $Z$ accelerator's vacuum-insulator stack to the location of the IVM (i.e., the $D$ level of the post-hole convolute). The agreement between the two techniques was found to be quite favorable, particularly in overall waveform shape, amplitude, and timing. However, the fluctuations in the IVM waveforms in this low-frequency approximation are larger than that of the TLE-translated case. Because of this, we employed a transit-time-correction technique and also used the IVM data from shot 2105 to find the characteristic frequency response of the IVM for implementation II. We were then able to use this frequency response to Fourier analyze the IVM data for the remainder of the shots that used this implementation. The use of the transit-time-correction technique of Eq. (4) and the Fourier analysis resulted in better agreement between the IVM data and TLE translations.

The general agreement found between the IVM data and the lossless TLE translations further demonstrates that large electrical powers are transmitted efficiently through the MITLs on $Z$. When combined with advanced simulation efforts, these measurements and analysis techniques will be useful for developing a better understanding of load behavior on $Z$.

\section{ACKNOWLEDGMENTS}

The authors thank two anonymous reviewers for their very helpful comments and suggestions, particularly for those related to approximating the inductance of the IVM probe. The authors also thank M. K. Matzen, M. C. Herrmann, and J. L. Porter for programmatic support, M. Cleveland, T. J. Rogers, D. Sandoval, R. L. Harmon, and A. C. Owen for their assistance with the design, analysis, and fabrication of the IVM-compatible debris inhibitor, M. Jones, M. R. Lopez, A. D. Edens, J. W. Weed, R. D. Thomas, and T. C. Wagoner for reviewing the IVM design for use on Z, T. D. Mulville, E. W. Breden, and the rest of the $Z$ center section crew for their technical assistance with fielding the IVM on $Z$, and the $Z$ operations, engineering, pulsed-power, diagnostics, LTGS support, CMDAS support, load hardware design, A. Maurer, L. Molina, and the rest of load hardware assembly, target fabrication, management, administrative support, and the dynamic material properties, $K$-shell x-ray sources, and ICF research groups for their general assistance with various activities on Z. Sandia is a multiprogram laboratory operated by Sandia Corporation, a Lockheed-Martin company, for the United States Department of Energy's National Nuclear Security Administration, under Contract No. DE-AC0494AL85000.

[1] D. H. McDaniel, M. G. Mazarakis, D. E. Bliss, J. M. Elizondo, H. C. Harjes, H. C. Ives, III, D. L. Kitterman, J. E. Maenchen, T. D. Pointon, S. E. Rosenthal, D. L. Smith, K. W. Struve, W. A. Stygar, E. A. Weinbrecht, D. L. Johnson, and J.P. Corley, in Proceedings of the 5th International Conference on Dense Z-Pinches, Vol. 651, edited by C. Deeney, N. R. Pereira, and J. Davis (AIP, Melville, NY, 2002), pp. 23-28.

[2] M. K. Matzen, B. W. Atherton, M. E. Cuneo, G. L. Donovan, C. A. Hall, M. Herrmann, M. L. Kiefer, R. J. Leeper, G. T. Leifeste, F. W. Long, G. R. McKee, T. A. Mehlhorn, J. L. Porter, L. X. Schneider, K. W. Struve, W. A. Stygar, and E. A. Weinbrecht, Acta Phys. Pol. A 115, 956 (2009).

[3] D. V. Rose, D. R. Welch, E. A. Madrid, C. L. Miller, R. E. Clark, W. A. Stygar, M. E. Savage, G. A. Rochau, J. E. Bailey, T. J. Nash, M. E. Sceiford, K. W. Struve, P. A. Corcoran, and B. A. Whitney, Phys. Rev. ST Accel. Beams 13, 010402 (2010).

[4] M. Savage, K. LeChien, M. Lopez, B. Stoltzfus, W. Stygar, D. S. Artery, J. Lott, and P. Corcoran, in Proceedings of the Pulsed Power Conference (PPC), 2011 (IEEE, New York, 2011), pp. 983-990.

[5] S. A. Slutz, M. C. Herrmann, R. A. Vesey, A. B. Sefkow, D. B. Sinars, D. C. Rovang, K. J. Peterson, and M. E. Cuneo, Phys. Plasmas 17, 056303 (2010).

[6] M. E. Cuneo, M. C. Herrmann, D. B. Sinars, S. A. Slutz, W. A. Stygar, R. A. Vesey, A. B. Sefkow, G. A. Rochau, G. A. Chandler, J. E. Bailey, J. L. Porter, R. D. McBride, D. C. Rovang, M. G. Mazarakis, E. P. Yu, D. C. Lamppa, K. J. Peterson, C. Nakhleh, S. B. Hansen, A. J. Lopez, M. E. Savage, C. A. Jennings, M. R. Martin, R. W. Lemke, B. W. Atherton, I. C. Smith, P. K. Rambo, M. Jones, M. R. Lopez, P. J. Christenson, M. A. Sweeney, B. Jones, L. A. McPherson, E. Harding, M. R. Gomez, P. F. Knapp, T. J. Awe, R. J. Leeper, C. L. Ruiz, G. W. Cooper, K. D. Hahn, J. McKenney, A. C. Owen, G. R. McKee, G. T. Leifeste, D. J. Ampleford, E. M. Waisman, A. Harvey-Thompson, R. J. Kaye, M. H. Hess, S. E. Rosenthal, and M. K. Matzen, IEEE Trans. Plasma Sci. 40, 3222 (2012).

[7] R. D. McBride, M. R. Martin, R. W. Lemke, J. B. Greenly, C. A. Jennings, D. C. Rovang, D. B. Sinars, M. E. Cuneo, M. C. Herrmann, S. A. Slutz, C. W. Nakhleh, D. D. Ryutov, J.-P. Davis, D. G. Flicker, B. E. Blue, K. Tomlinson, D. Schroen, R. M. Stamm, G. E. Smith, J. K. Moore, T. J. Rogers, G. K. Robertson, R. J. Kamm, I. C. Smith, M. Savage, W. A. Stygar, G. A. Rochau, M. Jones, M. R. Lopez, J. L. Porter, and M. K. Matzen, Phys. Plasmas 20, 056309 (2013). 
[8] T. J. Awe, R. D. McBride, C. A. Jennings, D. C. Lamppa, M. R. Martin, D. C. Rovang, S. A. Slutz, M. E. Cu neo, A. C. Owen, D. B. Sinars, K. Tomlinson, M. R. Gomez, S. B. Hansen, M. C. Herrmann, J. L. McKenney, C. Nakhleh, G. K. Robertson, G. A. Rochau, M. E. Savage, D. G. Schroen, and W. A. Stygar, Phys. Rev. Lett. 111, 235005 (2013).

[9] W. A. Stygar, S. E. Rosenthal, H. C. Ives, T. C. Wagoner, G. O. Allshouse, K. E. Androlewicz, G. L. Donovan, D. L. Fehl, M. H. Frese, T. L. Gilliland, M. F. Johnson, J. A. Mills, D. B. Reisman, P. G. Reynolds, C. S. Speas, R. B. Spielman, K. W. Struve, A. Toor, and E. M. Waisman, Phys. Rev. ST Accel. Beams 11, 120401 (2008).

[10] W. A. Stygar, P. A. Corcoran, H. C. Ives, R. B. Spielman, J. W. Douglas, B. A. Whitney, M. A. Mostrom, T. C. Wagoner, C. S. Speas, T. L. Gilliland, G. A. Allshouse, R.E. Clark, G. L. Donovan, T.P. Hughes, D. R. Humphreys, D. M. Jaramillo, M. F. Johnson, J. W. Kellogg, R. J. Leeper, F. W. Long, T. H. Martin, T. D. Mulville, M. D. Pelock, B. P. Peyton, J. W. Poukey, J. J. Ramirez, P. G. Reynolds, J. F. Seamen, D. B. Seidel, A. P. Seth, A. W. Sharpe, R. W. Shoup, J. W. Smith, D. M. Van De Valde, and R. W. Wavrik, Phys. Rev. ST Accel. Beams 12, 120401 (2009).

[11] E. A. Madrid, D. V. Rose, D. R. Welch, R. E. Clark, C. B. Mostrom, W. A. Stygar, M. E. Cuneo, M. R. Gomez, T. P. Hughes, T. D. Pointon, and D. B. Seidel, Phys. Rev. ST Accel. Beams 16, 120401 (2013).

[12] M. R. Gomez, M. E. Cuneo, J.-P. Davis, R. W. Lemke, R. D. McBride, R. B. Campbell, C. A. Jennings, W. A. Stygar, D. V. Rose, D. R. Welch, and E. A. Madrid, in Proceedings of the 19th IEEE Pulsed Power Conference (IEEE, Piscataway, NJ, 2013).

[13] M. E. Cuneo, E. M. Waisman, S. V. Lebedev, J. P. Chittenden, W. A. Stygar, G. A. Chandler, R. A. Vesey, E. P. Yu, T. J. Nash, D. E. Bliss, G. S. Sarkisov, T. C. Wagoner, G. R. Bennett, D. B. Sinars, J. L. Porter, W. W. Simpson, L. E. Ruggles, D. F. Wenger, C. J. Garasi, B. V. Oliver, R. A. Aragon, W. E. Fowler, M. C. Hettrick, G. C. Idzorek, D. Johnson, K. Keller, S. E. Lazier, J. S. McGurn, T. A. Mehlhorn, T. Moore, D. S. Nielsen, J. Pyle, S. Speas, K. W. Struve, and J. A. Torres, Phys. Rev. E 71, 046406 (2005).

[14] D. B. Sinars, R. Lemke, M. E. Cuneo, S. Lebedev, E. M. Waisman, W. A. Stygar, B. Jones, M. C. Jones, E. P. Yu, J. L. Porter, and D. F. Wenger, Phys. Rev. Lett. 100, 145002 (2008).

[15] D. J. Ampleford, B. Jones, C. A. Jennings, S. B. Hansen, M. E. Cuneo, A. J. Harvey-Thompson, G. A. Rochau, C. A. Coverdale, A. R. Laspe, T. M. Flanagan, N. W. Moore, D. B. Sinars, D. C. Lamppa, E. C. Harding, J. W. Thornhill, J. L. Giuliani, Y.-K. Chong, J. P. Apruzese, A. L. Velikovich, A. Dasgupta, N. Ouart, W. A. Sygar, M. E. Savage, J. K. Moore, R. Focia, T. C. Wagoner, K. L. Killebrew, A. D. Edens, G. S. Dunham, M. C. Jones, P. W. Lake, D. S. Nielsen, M. Wu, A. L. Carlson, M. D. Kernahan, C. R. Ball, R. D. Scharberg, T. D. Mulville, E. W. Breden, C. S. Speas, G. Olivas, M. A. Sullivan, A. J. York, D. W. Justus, J. C. Cisneros, T. Strizic, J. Reneker, M. Cleveland, M. P. Vigil, G. Robertson,
D. Sandoval, C. Cox, A. J. Maurer, D. A. Graham, N. B. Huynh, S. Toledo, L. P. Molina, M. R. Lopez, F. W. Long, G. R. McKee, J. L. Porter, and M. C. Herrmann, Phys. Plasmas 21, 031201 (2014).

[16] J. E. Bailey, G. A. Chandler, D. Cohen, M. E. Cuneo, M. E. Foord, R. F. Heeter, D. Jobe, P. W. Lake, J. J. MacFarlane, T. J. Nash, D. S. Nielson, R. Smelser, and J. Torres, Phys. Plasmas 9, 2186 (2002).

[17] J. E. Bailey, G. A. Rochau, R. C. Mancini, C. A. Iglesias, J. J. MacFarlane, I. E. Golovkin, C. Blancard, P. Cosse, and G. Faussurier, Phys. Plasmas 16, 058101 (2009).

[18] R. C. Mancini, J. E. Bailey, J. F. Hawley, T. Kallman, M. Witthoeft, S. J. Rose, and H. Takabe, Phys. Plasmas 16, 041001 (2009).

[19] G. A. Rochau, J. E. Bailey, R. E. Falcon, G. P. Loisel, T. Nagayama, R. C. Mancini, I. Hall, D. E. Winget, M. H. Montgomery, and D. A. Liedahl, Phys. Plasmas (to be published).

[20] M. D. Knudson, M. P. Desjarlais, R. W. Lemke, T. R. Mattsson, M. French, N. Nettelmann, and R. Redmer, Phys. Rev. Lett. 108, 091102 (2012).

[21] M. R. Martin, R. W. Lemke, R. D. McBride, J.-P. Davis, D. H. Dolan, M. D. Knudson, K. R. Cochrane, D. B. Sinars, I. C. Smith, M. Savage, W. A. Stygar, K. Killebrew, D. G. Flicker, and M. C. Herrmann, Phys. Plasmas 19, 056310 (2012).

[22] C. T. Seagle, J.-P. Davis, M. R. Martin, and H. L. Hanshaw, Appl. Phys. Lett. 102, 244104 (2013).

[23] J. L. Brown, C. S. Alexander, J. R. Asay, T. J. Vogler, D. H. Dolan, and J. L. Belof, J. Appl. Phys. 115, 043530 (2014).

[24] M. K. Matzen, M. A. Sweeney, R. G. Adams, J. R. Asay, J. E. Bailey, G. R. Bennett, D. E. Bliss, D. D. Bloomquist, T. A. Brunner, R. B. Campbell, G. A. Chandler, C. A. Coverdale, M. E. Cuneo, J.-P. Davis, C. Deeney, M. P. Desjarlais, G. L. Donovan, C. J. Garasi, T. A. Haill, C. A. Hall, D. L. Hanson, M. J. Hurst, B. Jones, M. D. Knudson, R. J. Leeper, R. W. Lemke, M. G. Mazarakis, D. H. McDaniel, T. A. Mehlhorn, T. J. Nash, C. L. Olson, J. L. Porter, P. K. Rambo, S. E. Rosenthal, G. A. Rochau, L. E. Ruggles, C. L. Ruiz, T. W. L. Sanford, J. F. Seamen, D. B. Sinars, S. A. Slutz, I. C. Smith, K. W. Struve, W. A. Stygar, R. A. Vesey, E. A. Weinbrecht, D. F. Wenger, and E. P. Yu, Phys. Plasmas 12, 055503 (2005).

[25] R. Spielman, P. Corcoran, J. Fockler, H. Kishi, and P. Spence, in Proceedings of the 7th Pulsed Power Conference, 1989 (IEEE, New York, NY, 1989), pp. $445-448$.

[26] T. C. Wagoner, W. A. Stygar, H. C. Ives, T. L. Gilliland, R. B. Spielman, M. F. Johnson, P. G. Reynolds, J. K. Moore, R. L. Mourning, D. L. Fehl, K. E. Androlewicz, J. E. Bailey, R. S. Broyles, T. A. Dinwoodie, G. L. Donovan, M. E. Dudley, K. D. Hahn, A. A. Kim, J. R. Lee, R. J. Leeper, G. T. Leifeste, J. A. Melville, J. A. Mills, L. P. Mix, W. B. S. Moore, B. P. Peyton, J. L. Porter, G. A. Rochau, G. E. Rochau, M. E. Savage, J. F. Seamen, J. D. Serrano, A. W. Sharpe, R. W. Shoup, J. S. Slopek, C. S. Speas, K. W. Struve, D. M. Van De Valde, and R. M. Woodring, Phys. Rev. ST Accel. Beams 11, 100401 (2008).

[27] W. Stygar, R. Spielman, H. Ives, W. Moore, J. Seamen, A. Sharpe, T. Wagoner, T. Gilliland, R. Broyles, J. Mills, 
T. Dinwoodie, J. Slopek, K. Struve, and P. Reynolds, in Proceedings of the 11th IEEE International Pulsed Power Conference, 1997, Baltimore, Vol. 2 (IEEE, Piscataway, NJ, 1997), p. 1258.

[28] D. V. Rose, D. R. Welch, C. L. Miller, R. E. Clark, E. A. Madrid, C. B. Mostrom, T. C. Wagoner, J. K. Moore, W. A. Stygar, J. E. Bailey, T. J. Nash, G. A. Rochau, and D. B. Sinars, Phys. Rev. ST Accel. Beams 13, 040401 (2010).

[29] E. M. Waisman, M. E. Cuneo, R. W. Lemke, D. B. Sinars, and W. A. Stygar, Phys. Plasmas 15, 042702 (2008).

[30] M.E. Savage, J. C. W. Mendel, T. W. Grasser, W. W. Simpson, and D. M. Zagar, Rev. Sci. Instrum. 61, 3812 (1990).

[31] C. A. Jennings, J. P. Chittenden, M. E. Cuneo, W. A. Stygar, D. J. Ampleford, E. M. Waisman, M. Jones, M. E. Savage, K. R. LeChien, and T. C. Wagoner, IEEE Trans. Plasma Sci. 38, 529 (2010).

[32] R. D. McBride, C. A. Jennings, R. A. Vesey, G. A. Rochau, M. E. Savage, W. A. Stygar, M. E. Cuneo, D. B. Sinars, M. Jones, K. R. LeChien, M. R. Lopez, J. K. Moore, K. W. Struve, T. C. Wagoner, and E. M. Waisman, Phys. Rev. ST Accel. Beams 13, 120401 (2010).

[33] D. G. Pellinen and M. S. Di Capua, Rev. Sci. Instrum. 51, 70 (1980).

[34] D. P. Murphy, R. J. Allen, B. V. Weber, R. J. Commisso, J. P. Apruzese, D. G. Phipps, and D. Mosher, Rev. Sci. Instrum. 79, 10E306 (2008).
[35] S. Ya. Belomyttsev, A. A. Grishkov, B. M. Kovalchuk, N. N. Pedin, and A. A. Zherlitsyn, Rev. Sci. Instrum. 82, 104702 (2011).

[36] G. M. Oleinik, Instrum. Exp. Tech. 43, 328 (2000).

[37] T. A. Shelkovenko, D. A. Chalenski, K. M. Chandler, J. D. Douglass, J. B. Greenly, D. A. Hammer, B. R. Kusse, R. D. McBride, and S. A. Pikuz, Rev. Sci. Instrum. 77, 10F521 (2006).

[38] R. D. McBride, T. A. Shelkovenko, S. A. Pikuz, D. A. Hammer, J. B. Greenly, B. R. Kusse, J. D. Douglass, P. F. Knapp, K. S. Bell, I. C. Blesener, and D. A. Chalenski, Phys. Plasmas 16, 012706 (2009).

[39] A. J. Harvey-Thompson, S. V. Lebedev, S. N. Bland, J. P. Chittenden, G. N. Hall, A. Marocchino, F. Suzuki Vidal, S. C. Bott, J. B. A. Palmer, and C. Ning, Phys. Plasmas 16, 022701 (2009).

[40] W. A. Johnson, L. I. Basilio, J. D. Kotulski, R. E. Jorgenson, L. K. Warne, R. Coats, D. Wilton, N. Champagne, F. Capolino, J. Grant, and M. Khayat, in Proceedings of the IEEE APS Symposium, Honolulu, Hawaii, 2007 (Curran Associates Inc., Red Hook, NY 2008).

[41] T. D. Pointon, Sandia National Laboratories, Albuquerque, NM, memorandum, November 17, 2008.

[42] W. H. Press, S. A. Teukolsky, W. T. Vetterling, and B. P. Flannery, Numerical Recipes in Fortran 77, Second Edition, The Art of Scientific Computing, Vol. I, subroutine dftint, p. 581 (Cambridge University, Cambridge, England, 2001). 